\title{
Research on Design of the Landscape inside Mountain Torrent Basin Based on Ecological Restoration - Take the Research Base in Wenling City, Zhejiang Province as an Example
}

\author{
Zhihao Zhang ${ }^{1}$, Xidong Ma ${ }^{1, *}$ \\ ${ }^{1}$ Zhejiang Sci-Tech University, Xiasha Higher Education Zone, 310018 Hangzhou City, Zhejiang province, China
}

\begin{abstract}
In order to reduce the ecological damage and economic loss caused by mountain torrent disasters in the flooded basin, it's very important to realize the self-repair of the ecosystem in a short time. Based on the analysis of the causes of mountain torrents, this paper summarizes three main parts of ecological restoration in the river basin, including rainwater storage, Sedimentation and wetland conservation. Taking a research base in Wenling, Zhejiang Province as an example, this paper also discusses the design methods of the landscape inside mountain torrent basins based on ecological restoration from these parts above. Finally, these methods were obtained and applied in design practice, providing more solutions and theoretical references for the ecological restoration design in the future.
\end{abstract}

\section{Introduction}

In recent years, the sudden and heavy rainfall has caused many natural disasters in the flood season, such as mountain torrents, debris flows and landslides. And it has caused serious ecological damage as well as economic losses to the river basin, which arises widespread concern from all walks of life ${ }^{[1]}$. The formation and eruption of these mountain torrent disasters are not only affected by natural factors, like heavy rainfall and geological characteristics, but also caused by excessive intervention of human factors such as construction activities ${ }^{[2]}$.

Through the analysis of the causes of mountain torrents, this paper summarizes the three main parts of ecological restoration in the basin, including rainwater storage, sedimentation and wetland conservation. And taking a research base in Wenling, Zhejiang Province as an example, this paper explores the design methods of the landscape inside mountain torrent basin based on ecological restoration. Finally, three theoretical design models, named Water Tree System, Zigzag Ditch and Habitat Archipelago, were obtained and applied in design practice, providing more solutions and theoretical references for the ecological restoration design in the future.

\section{Causes of mountain torrents}

Mountain torrents refer to explosion floods occurring in mountain creeks. The formation of mountain torrent disasters in various places mainly depends on the topographical and geological conditions of the mountain ${ }^{[3]}$. However, it is generally believed that natural factors and human factors are the two main causes of flash floods. The former include heavy rainfall and underlying surface conditions or so, and the latter mainly includes human unreasonable economic activities.

The heavy rainfall is the most active initial driving force for mountain torrents. What's more, the long-term rainfall will destroy the stability of rock formations and the soil on the surface of the mountain. The conditions of the underlying surface of the mountain include topography, geology, vegetation and other elements. Among them, the terrain conditions with steep slopes and large differences of elevation have the effect of increasing the potential energy of runoff and increasing the destructive power of mountain torrents. And for mountains with easily weathered bedrock, dissociation creates favorable conditions for collapse and debris flow. Besides, the sparse vegetation and the exposed rocks, which increase soil erosion, are also important factors leading to flash floods ${ }^{[4]}$

Long years ago, the disorderly and unreasonable development activities of the natural resources of the mountain by human beings caused the mountain to be devastated. A large number of naturally formed mountain ponds have undergone arbitrary development by humans. And their area has been drastically reduced, with the capacity of rainwater storage weakened severely. In the event of extreme rainfall, the runoff on the mountain surface will increase rapidly in a short time, which will pose a huge risk of flash floods to residential areas and farms around the mountain.

In 2017, the "Guiding Opinions on Strengthening Ecological Restoration Urban Rehabilitation" issued by the Ministry of Housing and Urban-Rural Development put forward the goal of ecological restoration: "Ecological restoration needs to implement the concept of sponge city construction, strengthen the protection of the natural form

Corresponding author: mxd2813@163.com 
of the urban water system, avoid blind transformation and over development, control river pollution, restore and maintain the natural connectivity and fluidity of the river and lake water system." ${ }^{[5,6]}$ It can be seen that ecological restoration aims to transform canalized rivers according to local conditions, restore natural shorelines as well as waterfront vegetation communities, and enhance the selfpurification capacity of water bodies.

For the ecological restoration of mountain torrents, it's vital to consider both natural and human factors. On the basis of satisfying human intervention, it's not only necessary to adopt various measures, like planting trees, to achieve rainwater conservation and mountain restoration, but also to carry out ecological conservation of the underlying surface to enhance the water purification capacity. Therefore, the ecological restoration design can be divided into three parts: rainwater storage on the mountain surface, sediment deposition and wetland conservation on the underlying surface, from the causes of mountain torrents. Then this paper takes a research base in Wenling to discuss the design methods of the landscape and restoration methods of mountain torrent basins based on ecological restoration.

\section{Project background}

Wenling City is located in East China, on the coast of southern Zhejiang Province. Affected by the regulation of the ocean water and the blocking of the cold currents by the northwest mountains, it has abundant rainfall and a mild climate. However, due to the East China Sea, a total of 43 typhoons have landed on Wenling City in the past 50 years, with an average annual rainfall of $1632 \mathrm{~mm}$, of which the rainfall during the typhoon period is about 840 $\mathrm{mm}$, accounting for $54.8 \%$ of the year ${ }^{[7]}$. And the heavy rainfall brought by typhoons has resulted in urban flooding and flash floods for many times, causing heavy economic losses and immeasurable damage to the ecosystem.

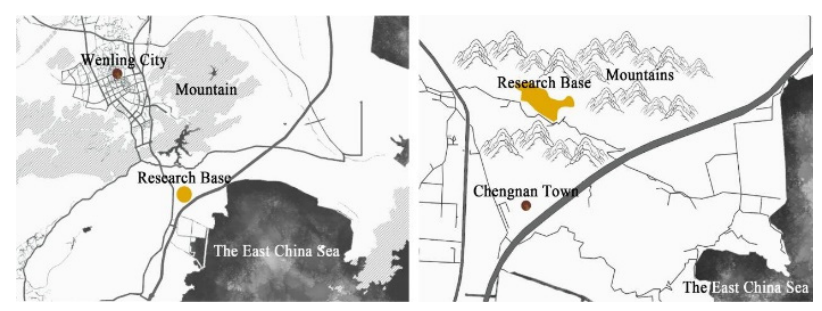

Fig1. The location of the research base.

As shown in Fig.1, the research base is located in a suburban scenic area of Chengnan Town, with only $4 \mathrm{~km}$ away from the East China Sea. And it's a typical mountain and hilly terrain, surrounded by mountains on three sides, and there is a creek passing through it. Because of the construction area built along, the mountain is the most important ecological element. The total land area is about $60750 \mathrm{~m}^{2}$.

For the last few years, the rapid development and construction process in the southern part of the city has neglected the natural elements, such as lakes and ponds. Then the blind development has severely damaged the original mountain drainage system and weakened its ability to regulate and store rainwater. At present, the flood interception design of the mountain is not yet sound. Therefore, when faced with sudden heavy rainfall, a large amount of rainwater would collect in the valley, scouring the shallow soil, and turn into flash floods finally. And the valley floor, through which the mountain torrents flowed, degenerates into a wasteland covered with sand and gravel slowly.

To sum up, in order to protect the rural scenery and biodiversity within the research base, it's very important to carry out the restoration design of the pond, mountain and the underlying surface of the valley to alleviate the risk of mountain torrents in the basin, with the regional water problem as the goal-oriented.

\section{Design method}

\section{1 "Water Tree" system: precipitation storage in layers}

On the treatment method of mountain rainwater storage, firstly, the team identified and stated the depressions in the mountains surrounding the base. These depressions include natural ponds, lakes and creeks, which are potential floodwater points. In order to achieve effective remediation and ensure the restoration, it is necessary to analyze the rainwater runoff flow direction and the catchment of the surrounding mountains in the early stage before fill and excavate according to local conditions. As shown in Fig.2, it's the current analysis of the depressions in the surrounding mountains of the base.
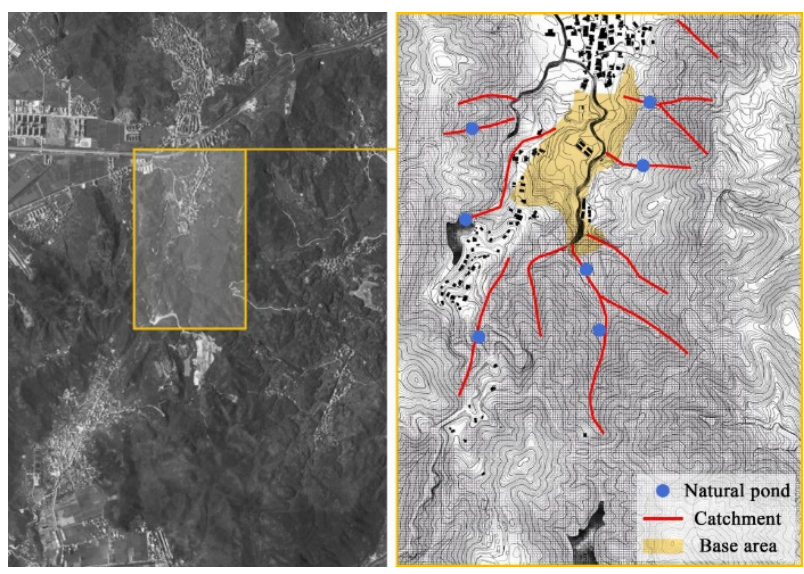

Fig2. The current analysis of the depressions in the surrounding mountains of the base.

For the protection and restoration of mountain ponds, the purpose is to improve the capacity of the mountain to regulate and store rainwater, so as to reduce the peak flow of mountain torrents and ensure the surrounding safety. And the specific protection and restoration strategy is shown in Fig.3. Firstly, the depressions on the water catchment line were repaired, combined with the previous analysis of rainwater runoff. And the main method is to expand existing mountain ponds appropriately and add small artificial ponds locally, which forms the "leaves" on the "water tree" system. Secondly, to enhance the "storage and detention" capacity of mountain ponds, walls are rammed on the periphery of mountain ponds to increase 
the storage capacity, intercept floods, and delay flood peaks. At last, ecological flood interception ditches should be constructed along the Catchment, connecting mountain ponds with adjacent depressions on the same catchment, to increase the storage space for mountain torrents. The connecting ditches between mountain ponds are like the "branches" of the "water tree" system.

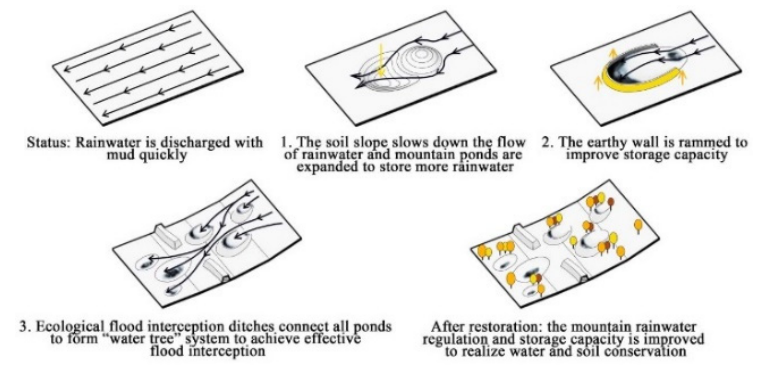

Fig3. The protection and restoration strategy of mountain ponds.

The function of the "Water Tree" system is to store rainwater in layers. When encountering extreme rainfall, rainwater will be stored in mountain ponds from top to bottom, which can intercept floods effectively and restrain soil erosion. Finally, only the excess rain will reach the valley and enter the next step of purification.

\subsection{Zigzag ditch: sedimentation and utilization}

Rainwater flows through the mountain with gravel and other impurities in it, which is the main cause of soil loss in the mountain. In this design, the valley floor is used as the construction land for the base. Therefore, how to combine the architectural design with the ecological restoration of the underlying surface is the key. The team used the rainwater filtration system in industrial production as a prototype and found that the precipitation effect of Sedimentation is determined by the flow rate of water and the residence time of the water in the sedimentation tank. And the zigzag streamline can provide a long streamline with a stable flow rate in a limited area.

As shown in Fig.4, the bottom floor of the building is used as a trench for rainwater precipitation, and unique architectural space is formed at the same time. Then the rainwater with impurities slowly flows into zigzag ditches at the bottom of the building for long-term sedimentation. Eventually, the sediment collects at the corners and becomes fertilizer for plant growth. Meanwhile, the clear rainwater flows out from the end of the building and spreads around the building. And plank roads are installed on the ditches to create an architectural space that blends with nature.

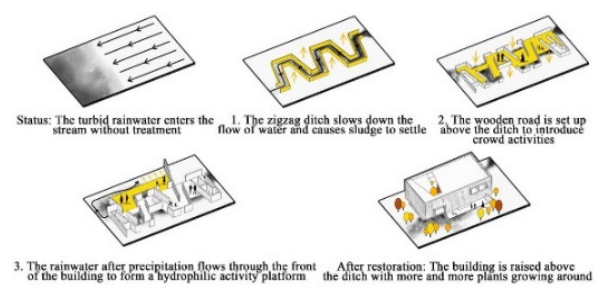

Fig4. The precipitation and utilization of sediment in rainwater.

\subsection{Habitat archipelago: wasteland landscape restoration}

The underlying surface of the valley floor is abandoned farmland. And due to a lot of gravel left by mountain torrents, there is almost no vegetation here. The team hopes to introduce the rainwater from the surrounding mountains into the base through manual control, which can replenish soil moisture, improve the local microclimate and enrich the habitat types of the research base. Exactly, the water in the base comes from rainwater from the mountains, which is a natural, ecological and reasonable way of using water resources.

On the basis of the original wild vegetation, the soil and stones in the wasteland were trimmed to form habitat islands, as shown in Fig.5. Having flowed through zigzag ditches of the building, the rainwater is introduced into the wasteland to form a seasonal wetland habitat. At the same time, on the basis of retaining better growing trees, native trees and shrubs with fruits will be planted to form a rich forest habitat, which is hoped to create habitats for birds as well as amphibians and also provide natural teaching places for research bases. The planting of native herbaceous plants, such as reeds and lotus, has a positive effect on the conservation of wetland water.

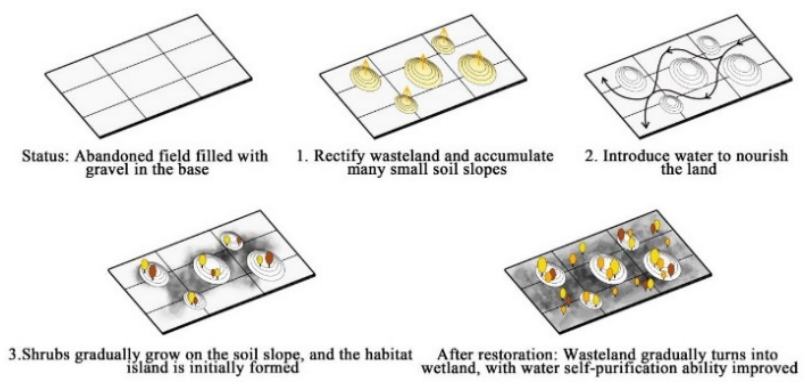

Fig5. The restoration of the wasteland at the bottom of the valley.

The establishment of the Habitat Archipelago not only reconstructs the self-renewal ability of nature, completes rainwater purification and soil conservation, but also shows the subtle and mysterious succession process of the natural ecosystem, becoming a place for tourists to experience the evolution of the natural and cultural landscape.

\section{Balanced linkage between ecological landscape and human activities}

The human activities that trigger mountain torrents are mainly the blind development of mountain resources, because people often sacrifice precious natural resources to obtain short-term economic benefits. As the economic artery of Chengnan town, the research base is located in the mountains, but intervening in nature in a reasonable and gentle way. The building and the mountain are fused, which means that the building becomes a container for the ecological restoration and the ecological settlements at the mountain become a part of the research base, to achieve the ideal state of harmonious coexistence.

After the base is completed, it will establish a cooperative relationship with surrounding schools and 
become a second classroom with "natural ecological science" as the main content. And as shown in Fig.6, combined with the three parts of ecological restoration, a variety of activities are implanted in the mountain. Around the mountain pond, multiple rest stations and sightseeing platforms can be set up to form nodes in the hiking and hiking route. What's more, there will be lots of workshops and exhibition halls on this base. People can make specimens by themselves and carry out simulation experiments about mountain torrents in the workshop, while the exhibition hall focuses on exhibiting specimens and introducing the formation of mountain torrents. In addition to indoor learning areas, the wetlands around the building community are also classrooms for people to study and get close to nature.

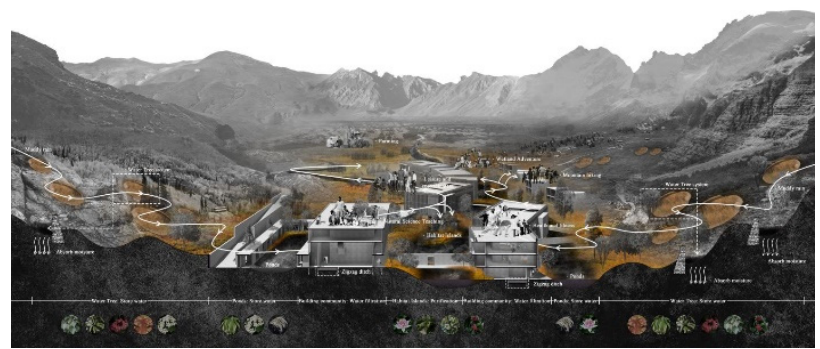

Fig6. The ecological landscape and human activities in the research base.

The research base will provide tourists and scholars with a platform to understand nature and complete courses on ecology and landscape, spreading and expanding the concept of sustainability among the younger generation. At the same time, the base steadily achieves profitability with the support of tourists, thereby achieving a healthy balance of the ecological environment, the social culture and economic benefits.

\section{Conclusion}

In recent years, the non-ecological development of mountains by humans has caused serious damage to the capacity of mountains to regulate the storage and intercept floods. And the triggered flash floods also caused immeasurable losses to residential areas around the basin. This paper analyzes the causes of mountain torrents at first and summarizes the three main parts of mountain ecological restoration. Furthermore, combined with a design case of a research base in Wenling City, Zhejiang Province, the methods of the landscape inside the mountain torrent basin were discussed based on the concept of ecological restoration.

In conclusion, before carrying out ecological restoration, it's necessary to analyze the restrictive construction elements of the mountain and grasp the natural conditions, such as the direction of rainwater and the current situation of mountain ponds. Secondly, stabilizing the water and soil through planting is a vital and effective measure, and it's also essential to transforming the existing mountain ponds to meet the requirements of rainwater storage. On the underlying surface of the valley bottom, the ecological flood interception channel and zigzag sedimentation ditch are connected in series to delay and weaken the flood peak during extreme rainfall, so as to reduce the impact of mountain torrents on the surrounding area. Finally, through improving the diversity of vegetation communities at the bottom of the valley, multiple habitat islands are set up to create a rich wetland habitat and achieve self-purification of water bodies.

\section{Acknowledgement}

This study was supported by the Student Science and Technology Foundations of Zhejiang Province (Code:2020R406029).

\section{References}

1. J. Chen, Current situation, problems and countermeasures of mountain torrent disaster prevention and control (China Water Resources Press, Beijing, 2016)

2. Z.T. Zhang, Mountain torrent disaster prevention measures and effectiveness (Water Resources and Hydropower Press, Beijing, 2016)

3. Z.L. Chen, Research on the causes and prevention technology of mountain torrent disasters in small watersheds (South China University of Technology, Guangzhou, 2014)

4. Q.L. Li, C.H. Huang, Heilongjiang Water Conservancy Science and Technology 28, 1 (2016)

5. X.X. Ren, W.Z. Tang, Sponge city runoff control rate and other indicators application (China Water Resources Press, Beijing, 2015)

6. X.H. Wang, Y.C. Zhang, P. Zhang, Water Resources Protection 12, 1 (2016)

7. Q. Wang, Research on the planning and design of urban green space in the Wenhuang Plain based on the concept of disaster reduction (Huazhong Agricultural University, Wuhan, 2017) 